\title{
Early Osseointegration Attained by UV-Photo Treated Implant into Piezosurgery-Prepared Site. Report III. Influence of Surface Treatment by Hydrogen Peroxide Solution and Determination of Early Loading
} Timing

\author{
Takashi Miyazaki ${ }^{1, *}$, Tomohiro Yutani ${ }^{1}$, Nanae Murai $^{1}$, Aya Kawata ${ }^{1}$, Haruka Shimizu ${ }^{1}$, Naru Uejima ${ }^{1}$, Yukiko Miyazaki ${ }^{1}$ and \\ Yoshiki Oshida \\ ${ }^{1}$ Miyazaki Dental Clinic, Kashiba-City, Nara Prefecture, Japan \\ ${ }^{2}$ Indiana University School of Dentistry, Professor Emeritus; University California San Francisco School of Dentistry, Adjunct Professor, San Francisco CA, \\ USA
}

*Corresponding author: Takashi Miyazaki, Director, Miyazaki Dental Clinic, Kashiba-City, Nara Prefecture, Japan, E-mail: miyarin3366@ gmail.com

Received: 15 Aug, 2021 | Accepted: 07 Sep, 2021 | Published: 13 Sep, 2021

Citation: Miyazaki T, Yutani T, Murai N, Kawata A, Shimizu H, et al. (2021) Early Osseointegration Attained by UV-Photo Treated Implant into Piezosurgery-Prepared Site. Report III. Influence of Surface Treatment by Hydrogen Peroxide Solution and Determination of Early Loading Timing. Int J Dent Oral Health 7(7): dx.doi.org/10.16966/2378-7090.381

Copyright: (c) 2021 Miyazaki T, et al. This is an open-access article distributed under the terms of the Creative Commons Attribution License, which permits unrestricted use, distribution, and reproduction in any medium, provided the original author and source are credited.

\section{Abstract}

Purpose: The aims of this study were (1) to investigate effectiveness of hydrogen peroxide treatment on early osseointegration, and (2) to determine the best timing for early loading.

Methods: Implants (originally sandblasted and acid-etched) were UV photofunctioned and placed in sites prepared by the piezosurgery. Out of 52 cases, 28 implant surfaces were subjected to $121^{\circ} \mathrm{C}_{2} \mathrm{O}_{2}$ solutions in an autoclave. Analysis on change rate during the healing period between implantation ISQ (ISQ-I) and loading ISQ (ISQ-L) was done on all 127 cases (including 35 from Part I and 40 from Part II studies and 52 from this study). ISQ data were analyzed to standardize the proper timing for early loading.

Results: Remarkable differences were not found among UV-treated, $\mathrm{H}_{2} \mathrm{O}_{2}$-treated and $\mathrm{UV}+\mathrm{H}_{2} \mathrm{O}_{2}$-treated groups and all are found within $\pm \sim 5 \%$ of change rate of ISQ readings. It was observed that (i) the majority of cases stay around zero at the ISQ change rate, (ii) however, 40 days and beyond, there seems to be an increasing trend. With respect to a proper timing for the early loading, it was found that, between healing times from 20 to 60 days, all data showed 60 or above of ISQ measured at the first loading.

Conclusion: It was concluded that (i) the higher ISQ-I is, the higher the change rate until the loading timing, and (ii) the proper timing for semi-early loading can be determined as follows; (1) if ISQ-I > 60, loading can be conducted on or after 30 days, (2) if $60>$ ISQ-I > 40, 40-day post-implantation can be long enough for the loading, and (3) if ISQ-I < 40, follow-up checking ISQ is recommended until the ' 40 days/60-ISQ criterion' is established.

Keywords: Commercially pure titanium grade IV implant; SA treatment; Hydrogen peroxide solution treatment; ISQ scale; Semi-early loading; UV photofunctioning; Piezosurgery

\section{Introduction}

Missing teeth compromise oral health, biofunction, and aesthetical appearance. Since the 1950s, dental implant treatments have become the gold standard in teeth replacement. Millions of individuals in the United States have experienced some degree of tooth loss; actually, more than 30 million people are missing all teeth in one or both maxilla and mandibular jaws [1]. It was reported that $69 \%$ of adults with age-ranging from 35 to 44 years old have lost at least one permanent teeth to an accident, gum disease, a failed root canal or tooth decay [2,3]. Furthermore, by age $74,26 \%$ of adults have lost all permanent teeth [4]. As a result, about 100,000-300,000 dental implants are placed every year, which approximates the numbers of artificial total hip and total knee joint arthroplasties per year [5]. It is obvious that appropriate dental implant treatment enhances patient's oral health related quality of life (OHRQoL). Even it is well recognized that, according to numerous clinical studies, the success rate of dental implants is 95 to $98 \%$, the success implant treatment should be supported by various important factors, including biocompatibility, biomechanical compatibility, and surface characteristics, implant design and surface modification, health condition and bone quality of a patient, and surgical techniques. All are, to different extents, related 
to an osseointegration. Figure 1 illustrates how all these factors are directly or indirectly related to each other to improve the quality of procedures, outcomes and prognosis of the implant treatment [6].

After placing implant(s), there are normally three protocols for a load timing: (1) immediate loading (within 48 hours), (2) early loading (2days to 3 months), and (3) conventional loading (3 to 6 months). The success of the implant treatment depends upon its osseointegration with the surrounding bone; namely, there should not be any progressive relative movement between the placed implant and the bone with which it has direct contact in biomechanistic environment. Immediate loading is proposed on an assumption that an initial primary stability can be achieved in the old bone and will change over time into the secondary stability in new and osseointegrated bone during the bone remodeling process [7]. Skvirsky Y [8] mentioned that there are five questions that dentists should ask themselves to determine whether to recommend delayed or immediate implant loading protocol to their patients and answers to each of question should be reflected to indication or contraindication for the immediate loading. They include (1) How important are the esthetics of the implanted teeth? (2) What is the condition of the patient's oral hygiene? (3) What is the occlusion and wear pattern of the patient's teeth? (4) How much bone grafting is required? (5) What implant surface treatment are you using? Questions 1 through 4 are related to patient's conditions, while the question 5 concerns the implant surface characteristics, which directly affect the early osseointegration of placed implants. Implant surfaces are modified to increase the rate of the osseointegration as well as the onset of primary and secondary stabilities. Surface modifications can include various surface engineering technologies such as sandblasting, shot-peening, acid- or alkaline-etching, metal powder or ceramic powder deposition, or a sequential combination of the above [9].

Aiming at the appropriate timing for an initial loading (some between immediate loading and early loading protocols), we have investigated the synergistic effect of photofunctionalization treatment by UV energy on the implant surface and a piezosurgery technique and reported that (i) the UV surface alteration and enough blood supply by piezosurgery preparation exhibited synergistic effects on improvement of ISQ scales, making the assured loading timing, and (ii) even lower the ISQ scale during the bone healing stage, they are still acceptable level for pursuing early loading [10]. Our subsequent study [11] investigated influences of age and gender of implant patients on an early osseointegration and reported that (i) number of elderly female implant patients were more than male patients, (ii) ISQ scales increased during the bone healing stage, independent of age and gender issues, and (iii) there is a critical value of ISQ for the successful implant treatment and it is at least 60 ISQ value. As mentioned before, a proper surface modification is powerful additional means to enhance the early osseointegration. Lim YJ and Oshida Y, et al., $[12,13]$ investigated the effect of hydrogen peroxide solution treatment on changes in surface roughness and resultant wettability on three biomedical $\mathrm{Ti}$ materials (commercially pure titanium: cpTi, Ti-6Al-4V, TiNi). It was found that (i) treatment in boiling $\mathrm{H}_{2} \mathrm{O}_{2}$ increased surface roughness and decreased surface contact angle (in other words, increase in the wettability) and (ii) thin oxide film formed on substrate surfaces of all Ti materials is a mixture of rutile and anatase types of $\mathrm{TiO}_{2}$, which is opposed to rutile only formed in dry oxidation condition and/or in acid-etching. Increased the wettability of Ti materials by $\mathrm{H}_{2} \mathrm{O}_{2}$ was further clarified by study by Agarwal P, et al., [14], evaluating the cement bond strength of cpTi pretreated by alumina-blasting, alumina-buff-polishing, $\mathrm{SiC}$ paper-polishing, in-air oxidation at 300C, in-air oxidation at $600^{\circ} \mathrm{C}$ and immersion in boiling $\mathrm{H}_{2} \mathrm{O}_{2}$ solution. It was found that the $\mathrm{H}_{2} \mathrm{O}_{2}$-treated surface exhibited the highest cement bond strength, due to effective surface roughness and a mixture of rutile and anatase types of $\mathrm{TiO}_{2}$ which enhanced surface wettability. The aims of the present study were (1) to investigate effectiveness of a hydrogen peroxide treatment on the early osseointegration, and (2) to determine the best timing for the early loading to standardize clinical principle.

\section{Materials and Method}

\section{Materials}

In Part I study [10], total 35 implants were placed, in which 33

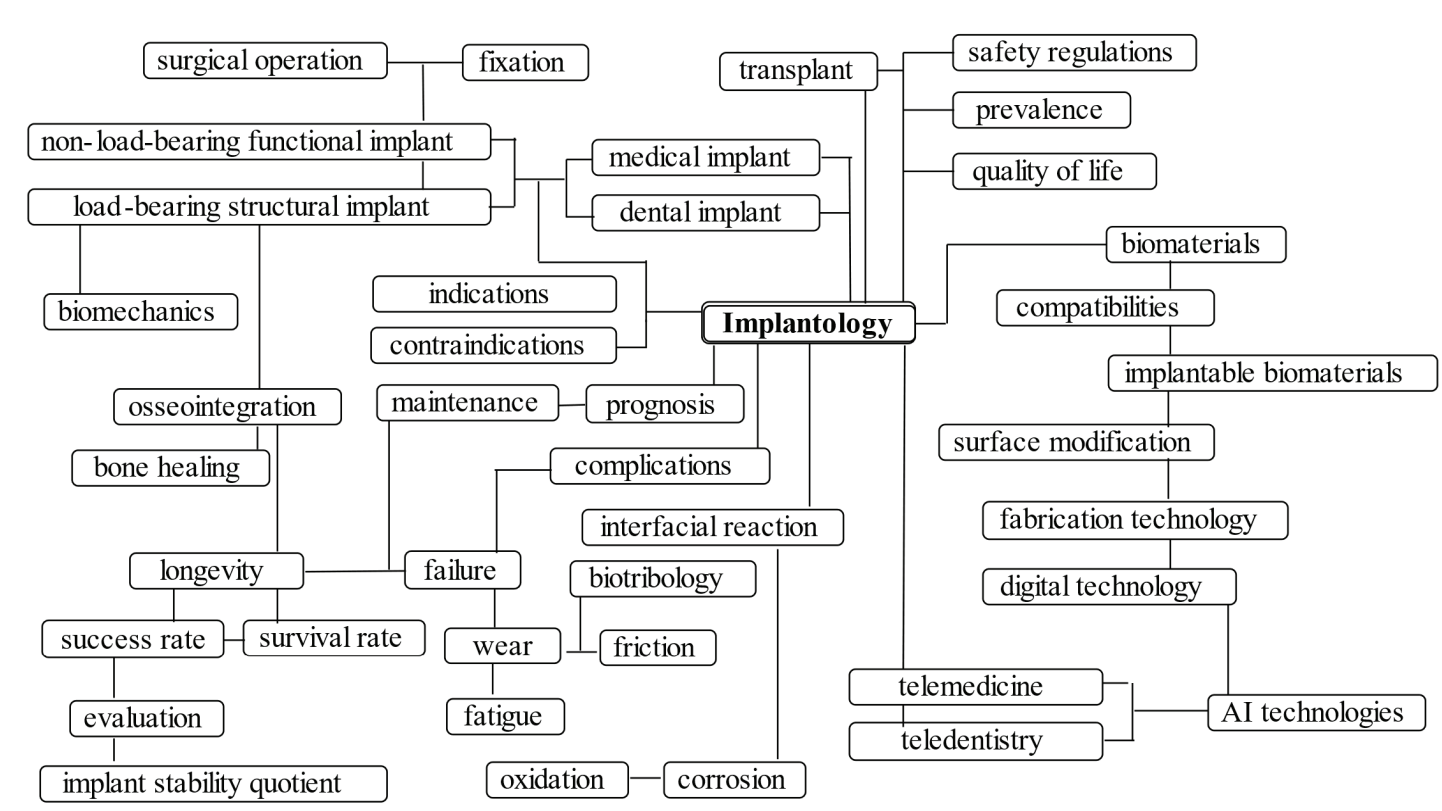

Figure 1: Implant map with various supporting factors [6]. 
implants were Osstem TS3 SA and 2 implants were Straumann Bone Level SLA. SA indicates that the implant surface was SAed (sand blasted with alumina particle, followed by an acid etching), while SLA means similarly that the surface of implants was subjected to sandblasted with large alumina grits, followed by acid etching. In Part II study [11], total 40 implants were placed, in which 31 Osstem implants (TS3, SS3) and 2 Shofu implants were SAed, and 7 Straumann implants (BLT, BL and TE) were SLAed. All implants were made of cpTi Grade IV. Diameter of all implants is larger than $4.0 \mathrm{~mm}$ and lengths are in a range from 7 to $8 \mathrm{~mm}$. In this Part III study, we added 52 implants, including 34 Osstem implants (TS3, TS4, SS3), 14 Neodent implants (GM), 1 Straumann implant (BLT), and 3 DIO implants (UVA). All implants were made of cpTi Grade IV. Diameter of all implants is larger than $4.0 \mathrm{~mm}$ and lengths are in a range from 7 to $8 \mathrm{~mm}$. Hence, this paper summarizes results of total 127 implants cases.

\section{UV photofunctionalization}

For treating implant surfaces, the commercially available TheraBeamAffiny UV system was utilized for 15 minutes for an automatic program of UV exposure.

\section{Hydrogen peroxide solution treatment}

Implants were treated in $2.5 \mathrm{w} / \mathrm{v} \%$ concentration $\mathrm{H}_{2} \mathrm{O}_{2}$ solution at $121^{\circ} \mathrm{C}$ for 10 minutes in the autoclave vessel. Thin oxide film formed on $\mathrm{H}_{2} \mathrm{O}_{2}$-treated implant was isolated from the substrate and was subjected to the transmission electron diffraction (at $150 \mathrm{kV}$ ) to identify the crystalline structures.

\section{Piezosurgery}

Mectron Piezosurgery II system was employed (Mectron SPA, Carasco, Italy). The average operation time was about 10 minutes including exchanging times of 4 to 5 insert chips. The load that patients can feel is so light that this operation normally does not provide any unnecessary anxiety on patients. The implant placement was performed by routine procedure, regardless of the surface conditions of implants and implant placement site preparation. Tooth extractions were performed as a traumatic as possible, followed by an immediate placement of implants. Local anesthesia was conducted through the local infiltration with the articaine (with adrenaline).

\section{ISQ scale evaluation}

The ISQ (implant stability quotient) is the value on a scale, indicating the level of stability and osseointegration in dental implants and is obtained using the resonance frequency analysis (RFA) [15]. In our studies, the OSSTELL ISQ system was used. The ISQ scales were measured at two directions, i.e., lingual and buccal sides. In table 1, a pair (for example, 77-80 for case No.1) indicates that ISQ 77 measured at lingual side and ISQ 80 obtained at buccal side. ISQ scale measurements were conducted at immediate after the implant placement (even before the suturing), designated as ISQ@I, and those measured at the time of the first loading, designated as ISQ@L, respectively. In addition, since the changes in ISQ scales between ISQ@I and ISQ@L (namely, $\triangle \mathrm{ISQ}$ ) should indicate an overall stability of placed implants, the change rates $(=[\Delta \mathrm{ISQ} / \mathrm{ISQ} @ \mathrm{I}] \times 100$ in \%) are also analyzed and proposed here to provide a useful implant stability indicator.

\section{Results}

Table 1 organizes all data on 52 placed implants. The following notations are used:

1) ISQ@I: ISQ scale was measured at immediately after implant placement before suturing.
2) Load: after certain days (as marked under "Days bet. I/L), the first loading was conducted.

\section{3) ISQ@L: ISQ scale was measured upon loading.}

4) $\triangle I S Q$ : the differences of ISQ scales between two readings: $\triangle I S Q$ = ISQ@L - ISQ@I.

5) $\triangle I S Q$ rate (for normalizing baseline): the $\triangle I S Q$ rate was obtained by $[\Delta \mathrm{ISQ} / \mathrm{ISQ} @ \mathrm{I}] \times 100(\%)$.

Total 127 cases (including 35 cases from Part I and 40 cases from Part II) are presented in ages and gender as illustrated in figure 2, in which there are 54 male patients and 73 female patients. As to an age distribution, we divided our implant patients into two groups: younger than 65 years old (total 69 patients $=41$ male +28 female) and older than 65 (total 58 patients $=13$ male +45 female). The reason for setting the age of 65 to separate two age groups is based on the fact that the age of 65 is one of commonly accepted 'age criterion' for entering aging society. In this study, it was found that young implant patients were more than the elderly ones, although the difference was not significant. In terms of gender, female patients appear to be less than male patients in young group; whist among elderly group, female patients are dominant, perhaps this might be due to (i) female's life expectancy of ten years longer than males 'one and (ii) esthetic reason.

Figure 3 illustrates $\triangle \mathrm{ISQ}$ rate in terms of days after the implant placement till the initial loading. Data points include those reported in Part I and Part II which were subjected to only UV treatment, while remaining 52 data points (in this Part III study) are reflected to three different surface treatments ( $\mathrm{UV}, \mathrm{UV}+\mathrm{H}_{2} \mathrm{O}_{2}$, and $\mathrm{H}_{2} \mathrm{O}_{2}$ ). One data point was followed sequentially because its initial ISQ value was very low; however it was observed that initial ISQ reading (52-59) was improved to reading (77-81) after 127 days (ca. 4 months).

Figure 4 shows detailed distribution of three different treatments on limited range of healing period (in other words, days until the initial loading). It was found that the majority of placed implants were stable within $\pm \sim 5 \%$ of change rate of ISQ readings with respect to their initial ISQ value, regardless of the type of surface treatment methods and gender.

\section{Discussion}

\section{Hydrogen peroxide solution treatment}

For successful osseointegration, the cleanliness of implant surfaces is considered as a crucial prerequisite. The SAL treatment involves alumina-sand blasting to increase effective surface area. Oshida $\mathrm{Y}$, et al., [16] elementally analyzed on recycled alumina powder, and reported that unused $\mathrm{Al}_{2} \mathrm{O}_{3}$ contains $100 \% \mathrm{Al}$, while used (accumulated usage time was about $2,400 \mathrm{sec}$ ) particles contained $\mathrm{Al}(83.32 \mathrm{wt} \%), \mathrm{Ti}(5.48)$, $\mathrm{Ca}$ (1.68), Ni (1.36), Mo (1.31), S (1.02), Si (0.65), P (0.55), Mn (0.49), $\mathrm{K}(0.29), \mathrm{Cl}(0.26)$, and $\mathrm{V}(0.08)$, strongly indicating that used alumina powder was heavily contaminated. Hence it can be speculated that the thus contaminated alumina power might cause further contaminate subsequent work pieces to be sandblasted if the sand blasting machine is the recyclable type. Such contaminants are from previously blasted materials having various chemical compositions and nozzle tip hard materials. It was mentioned that aluminum ions are suspected to impair bone formation by a possible competitive action to calcium $[17,18]$. This phenomenon was described around alumina coatings of cementless hip prosthetic stems. The presence of a consistent layer of decalcified bone tissue was demonstrated in continuity with and parallel to the prosthetic interface [19] and this demineralization has been attributed to a high concentration of aluminum ions $[19,20]$. 
Table 1: Summary of obtained data in terms of loading date, implant dimension and location, ISQ at placement and loading date and ISQ at loading.

\begin{tabular}{|c|c|c|c|c|c|c|c|c|c|c|c|}
\hline No. & Implant 2021 & Loc & Type & Treatment & Age & Sex & ISQ@I & Days bet. I/L & ISQ@L & $\Delta \mathrm{ISQ}$ & $\Delta \mathrm{ISQ}$ rate $(\%)$ \\
\hline 1 & $01 / 23$ & 15 & TS3 & $\mathrm{H}$ & $<60$ & $\mathrm{M}$ & $77-80$ & 35 & $76-76$ & -3 & -3.8 \\
\hline 2 & $01 / 23$ & 25 & TS3 & UV/H & $<60$ & $M$ & $74-80$ & 35 & $76-75$ & 0 & 0 \\
\hline 3 & $01 / 25$ & 16 & SS3 & $\mathrm{H}$ & $>60$ & $\mathrm{M}$ & $66-66$ & 26 & $67-68$ & 1 & 1.5 \\
\hline 4 & $02 / 06$ & 21 & TS3 & $\mathrm{UV} / \mathrm{H}$ & $<60$ & $\mathrm{M}$ & 09-09 & 90 & $86-62$ & 65 & 710 \\
\hline 5 & $02 / 18$ & 14 & GM & $\mathrm{H}$ & $<60$ & $\mathrm{M}$ & $79-79$ & 46 & 70-74 & -7 & -8.9 \\
\hline 6 & $02 / 18$ & 16 & GM & $\mathrm{H}$ & $<60$ & $\mathrm{M}$ & $52-59$ & 127 & 77-81 & 24 & 43.6 \\
\hline 7 & $02 / 18$ & 34 & GM & $\mathrm{UV} / \mathrm{H}$ & $<60$ & $M$ & $80-80$ & 39 & $76-76$ & -4 & -5.0 \\
\hline 8 & $02 / 18$ & 36 & GM & $U V / H$ & $<60$ & $\mathrm{M}$ & $66-67$ & 39 & 69-69 & 3 & 4.6 \\
\hline 9 & $02 / 26$ & 46 & TS4 & UV/H & $>60$ & $\mathrm{~F}$ & $81-81$ & 52 & $80-81$ & 0 & 0 \\
\hline 10 & $02 / 27$ & 15 & GM & $\mathrm{H}$ & $>60$ & $M$ & 77-77 & 37 & $78-78$ & 1 & 1.3 \\
\hline 11 & 03/01 & 44 & $\mathrm{GM}$ & $\mathrm{H}$ & $>60$ & $\mathrm{M}$ & $65-59$ & 84 & 57-57 & -5 & -8.1 \\
\hline 12 & 03/01 & 45 & $\mathrm{GM}$ & $\mathrm{H}$ & $>60$ & $M$ & $77-76$ & 42 & $76-76$ & 0 & 0 \\
\hline 13 & 03/06 & 15 & GM & UV/H & $>60$ & $\mathrm{~F}$ & $62-62$ & 56 & $70-70$ & 8 & 12.9 \\
\hline 14 & 03/06 & 16 & GM & $\mathrm{UV} / \mathrm{H}$ & $>60$ & $\mathrm{~F}$ & $53-52$ & 65 & $53-58$ & 2 & 3.9 \\
\hline 15 & $03 / 13$ & 22 & TS4 & UV/H & $<60$ & $\mathrm{M}$ & $63-63$ & 38 & 69-58 & 0 & 0 \\
\hline 16 & $03 / 15$ & 25 & TS3 & UV & $>60$ & $\mathrm{~F}$ & $66-65$ & 36 & $60-70$ & 0 & 0 \\
\hline 17 & $03 / 15$ & 26 & TS3 & UV & $>60$ & $\mathrm{~F}$ & $70-79$ & 36 & $69-77$ & 0 & 0 \\
\hline 18 & $03 / 18$ & 46 & $\mathrm{GM}$ & UV/H & $<60$ & $\mathrm{M}$ & 71-79 & 36 & $79-80$ & 4 & 5.3 \\
\hline 19 & $03 / 19$ & 46 & TS3 & UV/H & $<60$ & $F$ & $84-84$ & 81 & $81-81$ & -3 & -3.6 \\
\hline 20 & $03 / 26$ & 16 & TS3 & UV/H & $>60$ & $\mathrm{~F}$ & $57-63$ & 52 & $59-67$ & 3 & 5.0 \\
\hline 21 & $03 / 27$ & 12 & TS3 & $\mathrm{H}$ & $<60$ & $M$ & $77-77$ & 56 & $76-62$ & -8 & -10.4 \\
\hline 22 & $03 / 27$ & 22 & TS3 & $\mathrm{H}$ & $<60$ & $M$ & $76-76$ & 56 & 76-76 & 0 & 0 \\
\hline 23 & $03 / 27$ & 46 & TS3 & $\mathrm{H}$ & $<60$ & $M$ & $73-73$ & 42 & $81-82$ & 8 & 11.0 \\
\hline 24 & $04 / 03$ & 36 & TS4 & UV/H & $<60$ & $M$ & $82-83$ & 33 & $82-82$ & 0 & 0 \\
\hline 25 & $04 / 12$ & 25 & TS4 & UV/H & $>60$ & $\mathrm{~F}$ & $52-48$ & 45 & $72-81$ & 25 & 50.0 \\
\hline 26 & $04 / 13$ & 46 & SS3 & UV/H & $<60$ & $M$ & 73-79 & 30 & $66-75$ & -5 & -6.6 \\
\hline 27 & $04 / 17$ & 24 & TS4 & UV/H & $>60$ & $M$ & 64-61 & 37 & $65-65$ & 3 & 4.8 \\
\hline 28 & $04 / 17$ & 26 & SS3 & UV/H & $>60$ & $M$ & $68-73$ & 37 & $65-67$ & -4 & -5.7 \\
\hline 29 & $04 / 20$ & 46 & SS3 & UV/H & $>60$ & $M$ & $63-63$ & 46 & $74-74$ & 11 & 17.5 \\
\hline 30 & $04 / 22$ & 45 & SS3 & UV/H & $>60$ & $\mathrm{~F}$ & 74-74 & 36 & $76-79$ & 3 & 4.1 \\
\hline 31 & $04 / 23$ & 34 & SS3 & UV/H & $>60$ & $M$ & $66-62$ & 35 & $62-62$ & -2 & -3.1 \\
\hline 32 & $04 / 23$ & 36 & SS3 & UV/H & $>60$ & $M$ & $77-84$ & 35 & $72-73$ & -7 & -8.8 \\
\hline 33 & $04 / 27$ & 12 & GM & UV/H & $<60$ & $M$ & $78-68$ & 30 & $73-73$ & -1 & -1.4 \\
\hline 34 & $04 / 27$ & 22 & GM & UV/H & $<60$ & $M$ & $73-72$ & 30 & $76-65$ & -1 & -1.4 \\
\hline 35 & $04 / 30$ & 26 & GM & UV & $>60$ & $\mathrm{~F}$ & $59-59$ & 41 & $63-67$ & 5 & 8.5 \\
\hline 36 & 05/01 & 25 & TS3 & UV/H & $<60$ & $\mathrm{~F}$ & 79-79 & 42 & $72-72$ & -5 & -6.3 \\
\hline 37 & 05/08 & 27 & GM & UV/H & $>60$ & $M$ & $62-63$ & 72 & 64-64 & 2 & 3.2 \\
\hline 38 & $05 / 14$ & 47 & TS4 & UV/H & $<60$ & $M$ & $42-48$ & 74 & $57-57$ & 13 & 29.5 \\
\hline 39 & $05 / 20$ & 36 & UVA & UV & $<60$ & $\mathrm{M}$ & $76-77$ & 53 & 74-72 & -3 & -4.0 \\
\hline 40 & $05 / 21$ & 37 & TS3 & UV & $>60$ & $\mathrm{~F}$ & $43-43$ & 68 & $60-60$ & 17 & 39.5 \\
\hline 41 & $05 / 18$ & 25 & BLT & UV & $>60$ & $M$ & $56-67$ & 60 & $66-60$ & 3 & 4.9 \\
\hline 42 & $05 / 27$ & 36 & TS3 & UV/H & $>60$ & $\mathrm{~F}$ & $45-57$ & 55 & $73-73$ & 11 & 21.6 \\
\hline 43 & $05 / 28$ & 25 & TS4 & UV/H & $<60$ & $\mathrm{~F}$ & $36-30$ & 63 & $57-60$ & 25 & 75.8 \\
\hline 44 & $05 / 31$ & 26 & SS3 & UV & $<60$ & $M$ & $34-34$ & 43 & $62-62$ & 18 & 52.9 \\
\hline 45 & $06 / 03$ & 26 & UVA & UV & $>60$ & $\mathrm{~F}$ & $79-79$ & 40 & $74-75$ & -4 & -5.1 \\
\hline 46 & $06 / 11$ & 36 & SS3 & UV & $>60$ & $\mathrm{~F}$ & $64-63$ & 34 & $78-73$ & 9 & 14.3 \\
\hline 47 & $06 / 14$ & 24 & TS4 & UV & $>60$ & $\mathrm{~F}$ & 51-49 & 36 & $49-49$ & -1 & -2.0 \\
\hline 48 & $06 / 17$ & 36 & SS3 & UV/H & $>60$ & $M$ & $78-78$ & 39 & $80-80$ & 2 & 2.6 \\
\hline 49 & $06 / 21$ & 11 & UVA & UV & $<60$ & $\mathrm{~F}$ & $80-80$ & 35 & $75-75$ & -5 & -6.3 \\
\hline 50 & $06 / 22$ & 36 & SS3 & UV & $<60$ & $\mathrm{~F}$ & 84-84 & 38 & $83-82$ & -1 & -1.2 \\
\hline 51 & $07 / 09$ & 34 & TS4 & UVH & $>60$ & $M$ & $76-76$ & 31 & $81-81$ & 5 & 6.7 \\
\hline 52 & $07 / 09$ & 35 & TS4 & UVH & $>60$ & $M$ & $77-77$ & 31 & $78-77$ & 0 & 0 \\
\hline
\end{tabular}

Note:

TS3, TS4: OsstemSAed bone-level type implant

SS3: OsstemSAed tissue-level type implant

BLT: Straumann SLAed bone-level type Ti-Zr implant

GM: NEODENT helix type implant

UVA: DIO active implant 


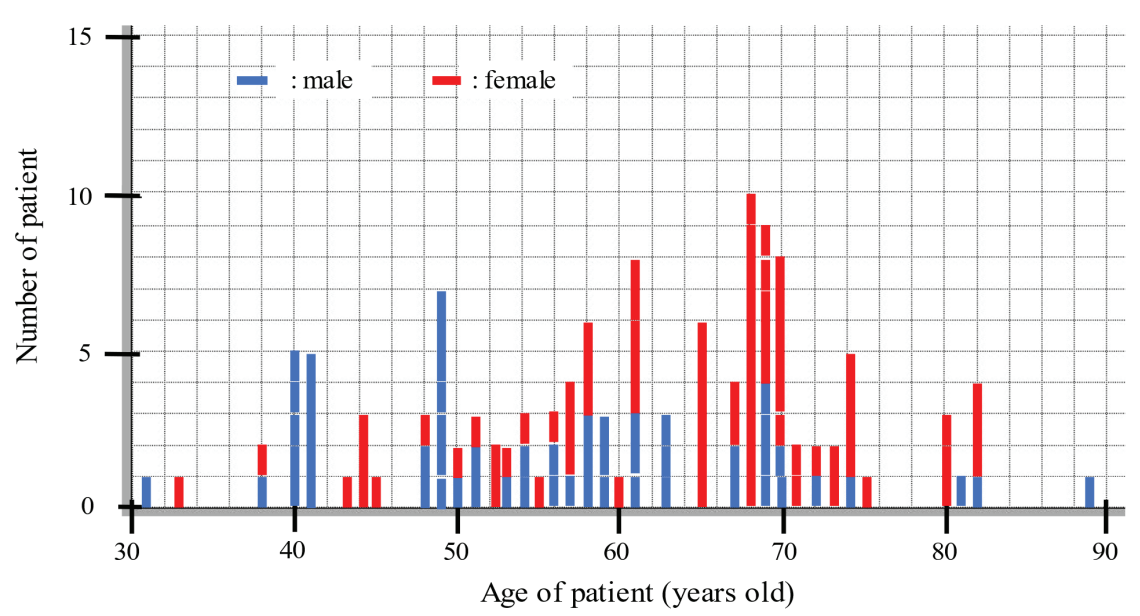

Figure 2: Patient distribution in terms of gender and age.

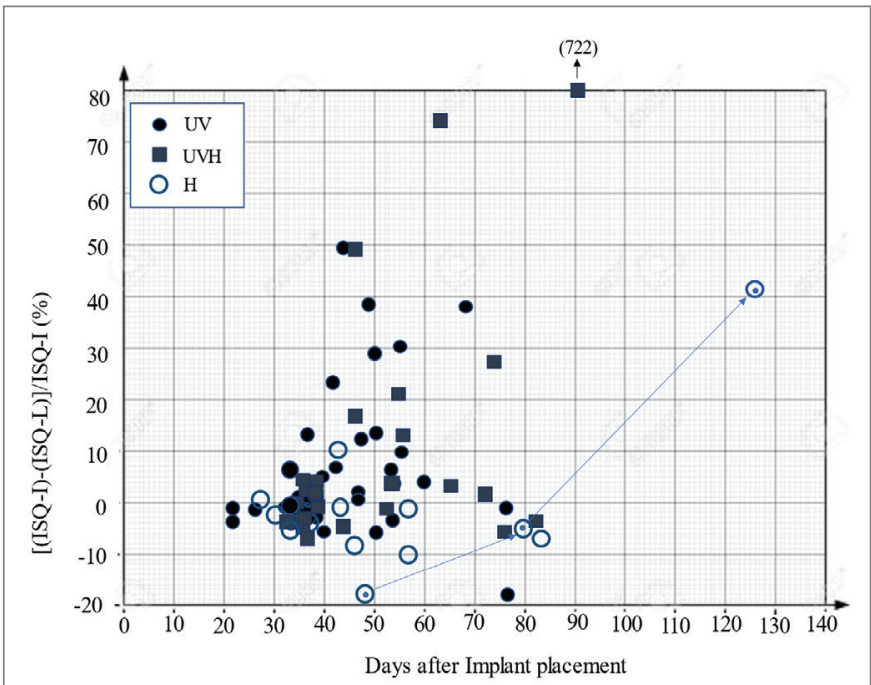

Figure 3: Change rate of ISQ value at the initial loading day, where UV: UV light treatment, UVH: UV light treatment followed by $\mathrm{H}_{2} \mathrm{O}_{2}$ treatment, and $\mathrm{H}: \mathrm{H}_{2} \mathrm{O}_{2}$ treatment.

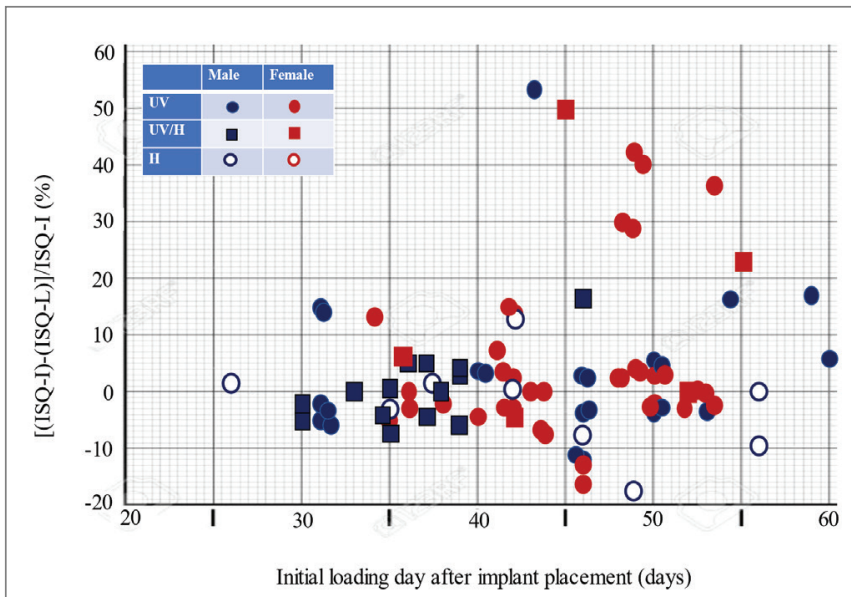

Figure 4: Detailed change rates in ISQ value during healing period between 20-day and 60-day.
Piattelli A, et al., [21] examined the effects of residual aluminum oxide particles on the implant surface on the integration of cpTi (Grade III) dental implants as compared to decontaminated implants in a rabbit experimental model (New Zealand white mature rabbit). The implants were sandblasted with $100 \sim 120 \mu \mathrm{m} \mathrm{Al}_{2} \mathrm{O}_{3}$ particles for 1 min, then 24 implants (control implants) underwent ASTM F 86-68 decontamination process in an ultrasonic bath. It was reported that, from histological results, residual aluminum oxide particles on the implant surface did not affect the osseointegration of titanium dental implants. Hence, the contamination issue is not clearly understood yet.

During the first 20 years of understanding the healing mechanisms of traumatized bone where implants are placed, the concept that a successful osseointegration was the result of titanium implant biocompatibility dominated clinical thinking. Subsequently, implant surface modifications encouraged new considerations of improvements in bone formation at the implant surface. Since the biological mechanisms at the bone-implant interface determine the fate of the implant, characteristics of the implant surface play a central role in challenging the process of the osseointegration with early loading [22]. In the present study, we applied hydrogen peroxide treatment to 32 implants out of new-cases of 52, with two-fold purposes: namely, (i) cleaning surfaces possibly contaminated with alumina powder, and (ii) increasing hybrid surface roughness. As shown in figures 3 and 4, it was found that there is no remarkable effect of the $\mathrm{H}_{2} \mathrm{O}_{2}$ treatment on ISQ values. Figure 5(a) shows a transmission electron diffraction pattern obtained from an oxide film which was formed on Ti implant after the $121^{\circ} \mathrm{C}$ for 10 minutes. It was found that the oxide was identified as a mixture of the rutile type and anatase type of $\mathrm{TiO}_{2}$ crystals. There is one more $\mathrm{TiO}_{2}$ crystal as known as brookite (the orthorhombic variant of titanium dioxide), but it is not stable in air. Although rutile type and anatase type share the same tetragonal crystalline system, the unit cell dimension is quite different from each other, as seen in figures 5(a) and 5(b). The unit cell of rutile type has $\mathrm{a}_{\mathrm{o}}=4.58 \AA$ and $\mathrm{c}_{\mathrm{O}}=2.98 \AA$, whist that of the anatase type has $\mathrm{a}_{\mathrm{o}}=3.78 \AA$ and $\mathrm{c}_{\mathrm{o}}=9.50 \AA \AA \mathrm{\AA}$ [23]. Although a-axis of both types are similar $(4.58 \AA$ vs. $3.78 \AA$ ), the c-axis of anatase $(9.50 \AA)$ is three times longer than that of the rutile type $(2.98 \AA)$. It is easily speculated that such a mixture of different unit cell sizes can form a hybrid nano-roughness on pre-blasted micro-rough surface. Accordingly, $\mathrm{SL}+\mathrm{H}_{2} \mathrm{O}_{2}$ treated surface exhibits a mixture of relatively macro-scale roughness caused by sandblasting and hybrid micro/ nano-scale roughness caused by $\mathrm{H}_{2} \mathrm{O}_{2}$ treatment, as illustrated in figure 


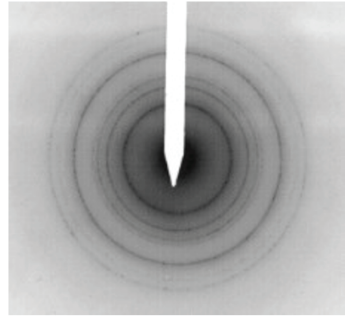

ED of rutile only

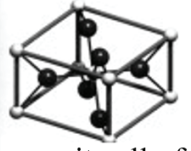

unit cell of rutile

(a)

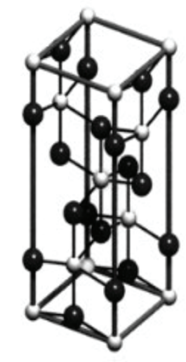

unit cell of anatase

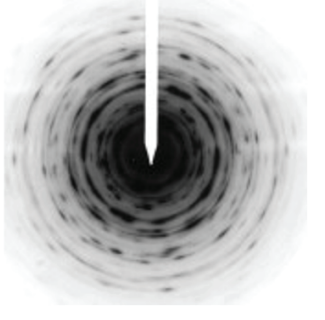

$\mathrm{ED}$ of rutile + anatase

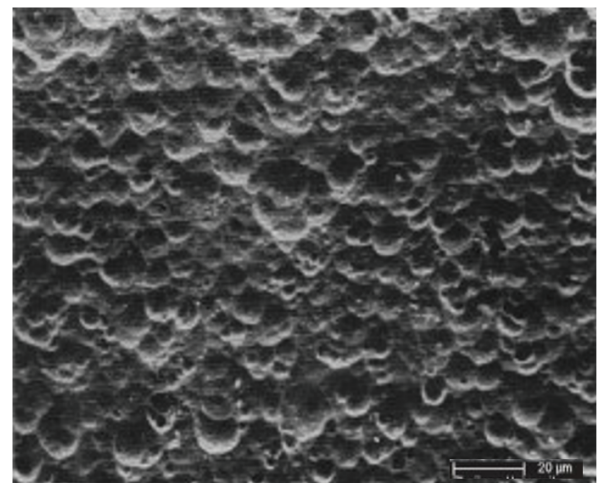

(c)

Figure 5: Electron diffraction pattern and unit cell of identified crystal structure of oxide film formed on as-received implant surface, showing rutile type $\mathrm{TiO}_{2}$ (a) and oxide formed on $\mathrm{H} 2 \mathrm{O} 2$ treated implant surface, showing rutile and anatase mixed patterns (b), along with (c) SEM image of macro-scale and micro/nano-scale hybrid surface configuration.

5(c). Unfortunately, in this study, this beneficial surface modification can't be revealed clearly with respect to the implant stability (in terms of initial ISQ value as well as loading ISQ value).

\section{Healing process and stability}

The implant stability is a prerequisite characteristic of the osseointegration. Continuous monitoring in quantitative and objective manners is important to determine the implant stability [24,25]. The osseointegration is also a measure of implant stability which can occur in two stages: primary and secondary [26]. Referring to figure 6 , the primary stability mostly occurs from a mechanical engagement with the cortical bone. A key factor for the implant primary stability is the bone-to-implant (BIC) [27], so that the primary stability is affected by bone quality and quantity, the surgical technique and implant geometry (length, diameter, surface characteristics) [28,29]. The secondary stability offers a biological stability through the bone regeneration and remodeling processes [30-33]. The secondary stability is affected by the primary stability [32,34]. During the transition period from the primary to the secondary stability, placed implants may face the risk of micromotion; possibly leading to an implant failure. In figure 6, detailed processes involved in the primary stability and onset of the secondary stability [35] are inserted. During the bleeding phase, which lasts for a few hours, it is normally that the more vascular the tissues, the longer they will bleed. The followings are major characteristics associated with the inflammatory phase: (i) essential for tissue repair, (ii) rapid onset (few hours) and increases in magnitude for 2 to 3 days before gradually resolving over a few weeks, (iii) complex, chemically mediated amplification cascades should be responsible for the initiation and control of the inflammatory reaction, and (iv) vascular and cellular cascades are the two essential elements. The proliferation phase can be characterized by (i) involvement of repair material generation, (ii) rapid onset for 24 to 48 hours, (iii) peak activity reached in 2 to 3 weeks, (iv) decrease over several months, (v) two fundamental processes: fibroplasia and angiogenesis, and (vi) chemical mediators, i.e., macrophage-derived growth factors, plateletderived growth factors, lactic acid, fibroblast growth factor. During the remodeling stage, there are several principle characteristics, including (i) primarily involves collagen and the extracellular matrix, (ii) with maturity, collagen becomes more oriented in line with local stress, and (iii) the type III collagen, which is fine, weak, and highly cellular (it is the collagen of granulation tissue and produced by young fibroblasts) is converted to type I collagen, which is more cross-linked with greater tensile strength and, therefore, more stable [35].

After roughly 2 to 3 weeks in post-implantation, the osteoclastic activity decreases the initial mechanical stability of the placed implant(s) but not enough new bone has been produced to provide an equivalent or greater amount of compensatory biological stability $[27,36]$. This is related to the biologic reaction of the bone to a surgical trauma during the initial bone remodeling phase; bone and necrotic materials resorbed by osteoclastic activity is reflected by a reduction in ISQ value. This process is followed by new bone apposition initiated by osteoblastic activity, therefore leading to adaptive bone remodeling around the implant [37]. Figure 7 confirms this statement, indicating that the higher the initial ISQ value is, the lower the progressive decrease rate of ISQ value during the bone healing process. It was also found that the majority data belong to a zone where initial ISQ-I at implantation is over 60 .

Figure 8 depicts a semi-linear relationship between initial ISQ (ISQ-I) at the implantation and ISQ-L at loading and this finding confirms one of conclusions reported by Suzuki S, et al. [38]. It is true that implant stability is one of the most important factors for the success of implant treatments. Although most studies showed a correlation between the bone density and the implant stability, some studies suggest the opposite; due to the differences in the methods used. Recent studies suggest that the implant stability during the healing process only increases for implants with low initial stabilities; meanwhile, a loss of stability during the healing stage can be observed in implants with high initial stabilities [39].

\section{Loading timing}

As mentioned in the introduction section, there are normally three protocols for the loading timing after implant placements: immediate loading (within 48 hours), early loading (2days to 3 months), and (3) conventional loading ( 3 to 6 months). According to figure 6 , the immediate loading is conducted during the primary stability, which is 


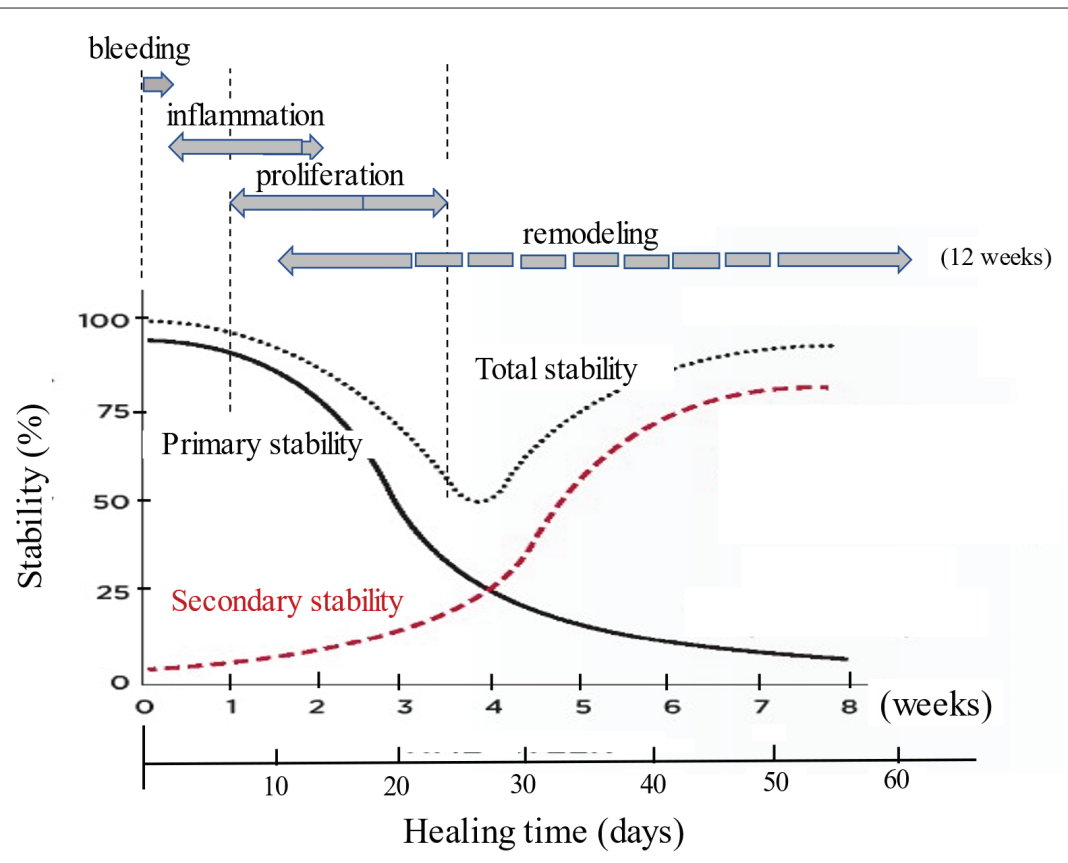

Figure 6: Conceptual diagram of primary stability (due to old bone) and secondary stability (due to new bone) during the healing period of traumatized bone with placed implant $[7,35]$.

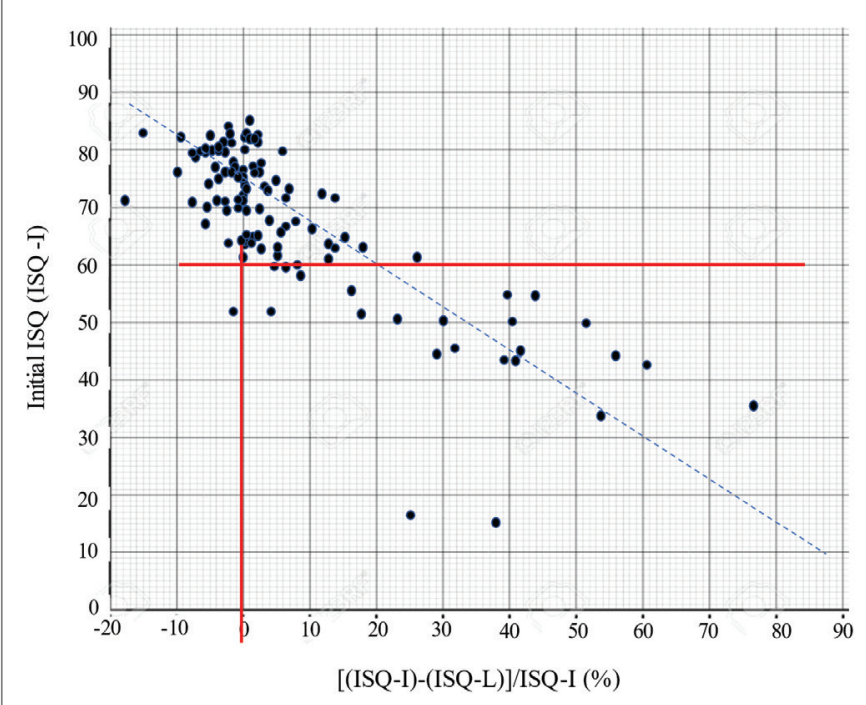

Figure 7: Relationship between initial ISQ at implantation and change rate of ISQ during the healing stage.

totally a function of the mechanical retention and heavily influenced by the implant design and dimension, as well as the density and volume of the traumatized bone. Therefore, appropriate osteotomy preparation is considered as a prerequisite for successful immediate loading. The primary stability gradually decreases and the secondary stability (due to biological stability through bone regeneration and remodeling processes) starts and increases, resulting in that these two competing processes create graphically a dip in the total stability curve, before which the primary is dominant, while after which the secondary is. An importance of the implant site preparation is crucial for particularly the primary stability since a thermal damage during bone drilling and compression of the bone in the osteotomy site can cause the osteocyte death followed by severe bone resorption and

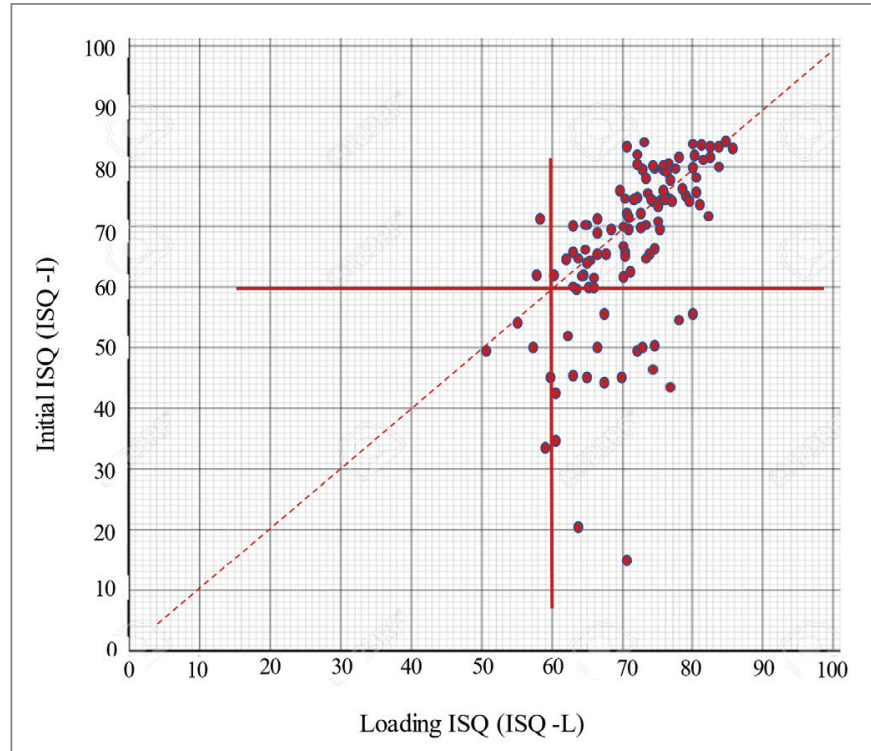

Figure 8: A relationship between ISQ-I and ISQ-L.

remodeling, which can ultimately compromise the implant stability in the weeks after placement [40].

Since these curves shown in figure 6 are conceptual, the transient timing from the primary to the secondary should be affected by various anatomical factors and surface modifications of placed implants. It is reported that the transient will take place typically 6 weeks of the healing process [41,7]. Suzuki S, et al., [38] reported that (i) the use of photofunctionalization eliminated the stability dip (in other words, no clear transient from primary to secondary stability) because of faster (when the primary stability is high) and even faster (when the primary stability is low) development of secondary stability and (ii) the dip can shift horizontally with respect to the healing time axis. 


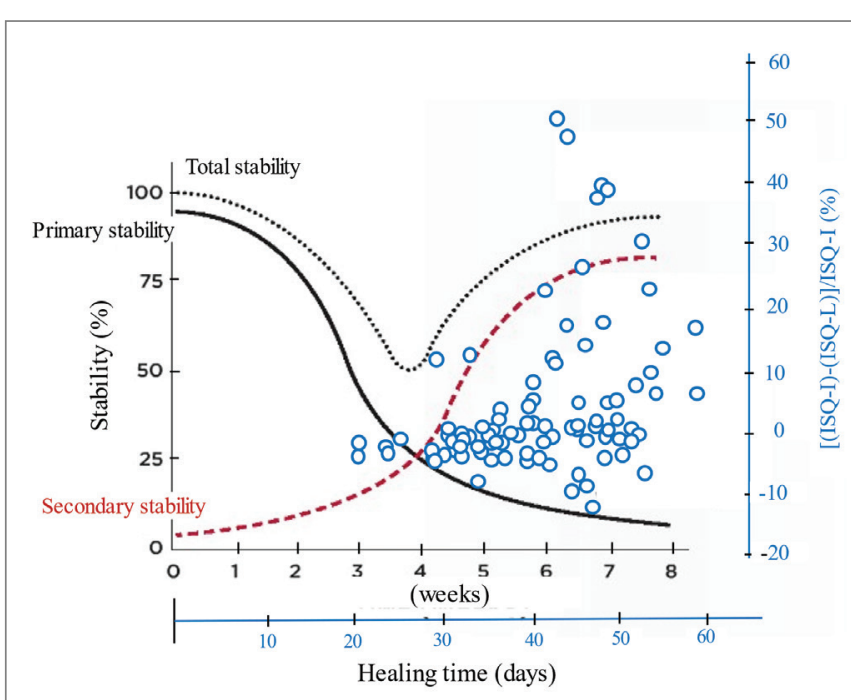

Figure 9: Change rate of ISQ between implantation ISQ and loading ISQ, superimposed to conceptual two-stage stability.

Besides these, an implant site preparation should be considered in terms of its influence in the stability phenomenon. Implant sites should be prepared using gentle, a traumatic surgical techniques with a constant reminder to avoid an overheating the bone. Conventional implant site preparation by the rotary drilling of the bone without a proper cooling may generate debris, increased temperature, bleeding, and hematoma formation that could injure the bone and increase a risk of the implant failure. An alternative for a site preparation is the piezosurgery (an ultrasonic vibrating cutting technology), which achieves accurate cuts while avoiding the disadvantages of conventional drilling [42-44]. Vercellotti T, et al., [45] reported on the multi-center study, indicating that more than 3,579 implants piezoelectric preparation has proven successful in a wide range of indications. All implants were placed into 1,885 subjects and it was found that (i) no surgical complications related to the implant site preparation were reported for any of the implant sites, (ii) 78 implants (59 maxillary, 19 mandibular) failed within 5 months of insertion, for an overall osseointegration percentage of $97.82 \%$ (97.14\% maxilla, 98.75\% mandible) and (iii) three maxillary implants failed after 3 years of loading, with an overall implant survival rate of $97.74 \%$ (96.99\% maxilla, 98.75\% mandible). Stacchi C, et al., [46] investigated the stability changes of implants inserted using traditional rotary instruments or piezoelectric inserts, and to follow their variations during the first 90 days of healing and concluded that (i) ultrasonic implant site preparation results in a limited decrease of ISQ values and in an earlier shifting from a decreasing to an increasing stability pattern, when compared with the traditional drilling technique and (ii) from a clinical point of view, a favorable effect of the piezoelectric preparation has been identified on the osseointegration, which results in an earlier transition from the primary to the secondary implant stability.

In this study, two beneficial efforts were mainly included in the implant treatment, namely, (1) the UV-treatment along with additional hydrogen peroxide treatment to enhance the surface physiochemistry and topological configuration, and (2) the piezoelectric oral surgery for an implant site preparation. According to what we have learned cited articles in the above, each of these or synergistically both of these could exhibit beneficial influences directly or indirectly on the osseointegration, so that an early loading can be achieved safely

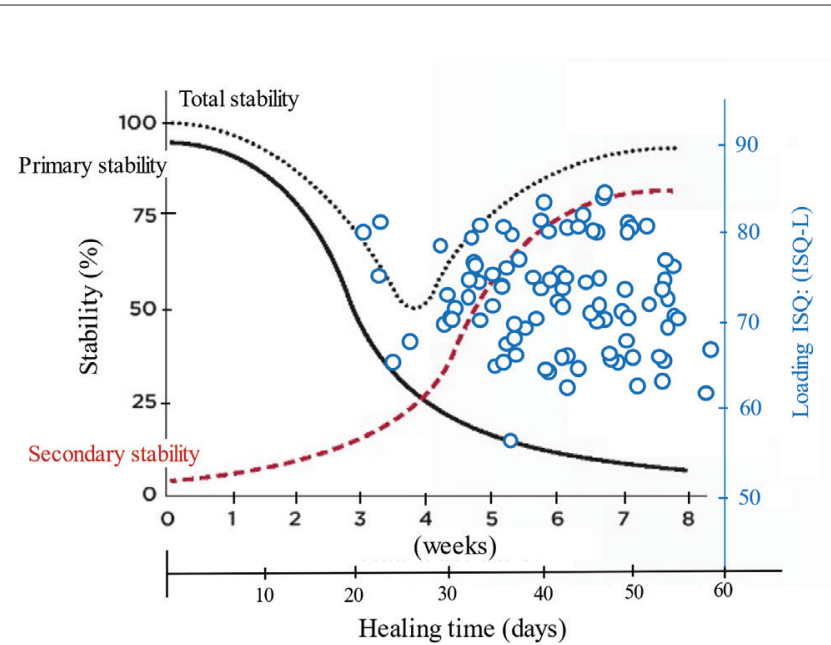

Figure 10: Loading ISQ, superimposed to conceptual two-stage stability.

and effectively. Figure 9 shows conceptual two-stage stability and the present data (limited for healing time from 20 days to 60 days) superimposed thereon. The right-side vertical axis position for ISQ change rate is chosen arbitrarily. It was observed that (i) a majority of cases stays around zero at the ISQ change rate, (ii) however, 40 days and beyond, there seems to be an increasing trend although it is not clear, at this moment, this trend is affected and related to an onset of the secondary stability phenomenon. To try to find the appropriate timing for loading, we further added same group cases as figure 9 but this time we used loading ISQ (ISQ-L), added to the two-stage stability graph, as seen in figure 10. Again, the location of vertical ISQ-L axis was arbitrarily determined. It was found that, between healing times from 20 to 60 days, all data (except one case with 54 of ISQ-L) show 60 or above of ISQ measured at the first loading.

\section{Conclusions}

Within limited number of implant patient cases, it was concluded that (i) the UV surface alteration and enough blood supply by the piezosurgery preparation exhibited synergistic effects on improvement of ISQ scales, indicating that these dual techniques appear applicable to implant treatments, (ii) number of elderly female implant patients were more than male patients, and (iii) additional hydrogen peroxide treatment did not exhibit remarkable effect on the osseointegration in terms of ISQ values. Summarizing all necessary information on ISQ values, the proper timing for semi-early loading can be determined and standardized as follows; (1) if ISQ-I > 60, as shown in the area of left upper square in figure 5 , loading can be conducted on or after 30 days, per suggestions from figure 10, (2) if $60>$ ISQ-I $>40$, as shown in the area of right down square in figure 5 , from indications from figures 8 and 10, 40-day post-implantation can be long enough for the loading, and (3) if ISQ-I $<40$, follow-up checking ISQ is recommended until '40 days/60-ISQ criterion' is established.

\section{References}

1. American Academy of Implant Dentistry. About Dental Implants.

2. Sullivan RM (2001) Implant dentistry and the concept of osseointegration: a historical perspective. J Calif Dent Assoc 29: 737-745. 
3. Mijiritsky E, Mazor Z, Lorean A, and Levin L (2013) Implant diameter and length influence on survival: interim results during the first 2 years of function of implants by a single manufacturer. Implant Dent 22: 394-398.

4. Gaviria L, Salcido JP, Guda T, and Ong JL (2014) Current trends in dental implants. J Korean Assoc Oral Maxillofac Surg 40: 50-60.

5. Gupta A, Dhanraj M, and Sivagami G (2010) Status of surface treatment in endosseous implant: a literary overview. Indian J Dent Res 21: 433-438.

6. Oshida Y. unpublished data. 2021.

7. Raghavendra S, Wood MC, and Taylor TD (2005) Early wound healing around endosseous implants: a review of the literature. Int J Oral Maxillofac Implants 20: 425-431.

8. Skvirsky Y (2020) Five (5) questions to ask before choosing between delayed and immediate dental implant loading. Dentistry iQ.

9. Oshida $Y$ (2014) Surface Engineering and Technology for Biomedical Implants. Momentum Press, New York, USA.

10. Miyazaki T (2020) Early Osseointegration Attained by UV-Photo Treated Implant into Piezosurgery-Prepared Site Report I. Retrospective Study on Clinical Feasibility. Int J Dent Oral Health 7: 1-7.

11. Miyazaki T, Yutani T, Murai N, Kawata A, Shimizu H, et al. (2021) Early Osseointegration Attained by UV-Photo Treated Implant into Piezosurgery-Prepared Site Report II. Influences of Age and Gender Int J Dent Oral Health. 7: 1-7.

12. Lim YJ, Oshida Y, Andres CJ, and Barco MT (2001) Surface characterization of variously treated titanium Materials. Int J Oral Maxillofac Implants 16: 333-342.

13. Lim YJ, Oshida Y (2001) Initial Contact Angle Measurements on Variously Treated Dental/Medical Titanium Materials. Biomed Mater Eng 11: 325-341.

14. Agarwal P, Oshida Y, Ito M (2005) Effects of Surface Modification of Ti on Cement Bond Strengths. Medical Device Materials II: Proceedings of the Materials \& Processes for Medical Devices Conference. Heat Treating Society, ASM International.

15. Pagliani L, Sennerby L, Petersson A, Verrocchi D, Volpe S, et al. (2013) The relationship between resonance frequency analysis (RFA) and lateral displacement of dental implants: an in vitro study. J Oral Rehabil 40: 221-227.

16. Oshida Y, Munoz CA, Winkler MM, Hashem A, Ito M (1993) Fractal Dimension Analysis of Aluminum Oxide Particle for Sandblasting Dental Use. J. Biomed Mater Eng 3: 117-126.

17. Esposito M, Hirsch JM, Lekholm U, Thomsen P (1998) Biological factors contributing to failures of osseintegrated oral implants: (II) Etiopathogenesis. Eur J Oral Sci 106: 721-764.

18. Nimb L, Jensen JS, Gotfredsen K (1995) Interface mechanics and histomorphometric analysis ofhydroxyapatite-coated and porous glass-ceramic implants in canine bone. J Biomed Mater Res 29: 1477-1482.

19. Toni A, Lewis CG, Sudanese A, Stea S, Calista F, et al. (1994) Bone demineralization induced by cementless alumina-coated femoral stems. J Arthroplasty 9: 435-444.

20. Savarino L, Cenni E, Stea S, Donati ME, Paganetto G, et al. (1993) $X$-ray diffraction of newly formed bone close to alumina or hydroxyapatite-coated femoral stem. Biomaterials 14: 900-905.

21. Piattelli A, Degidi M, Paolantonio M, Mangano C, Scarano A (2003) Residual aluminum oxide on the surface of titanium implants has no effect on osseointegration. Biomaterials 24: 4081-4089.
22. Ramazanoglu M, Oshida Y (2011) Osseointegration and Bioscience of Implant Surfaces-Current Concepts at Bone-Implant Interface. In: Turkyilmaz I (ed) Implant Dentistry-A Rapidly Evolving Practice. IntechOpen.

23. Wyckoff RWG (1931) The Structure of Crystals. New York: Chemical Catalog Co., 134,239.

24. Albrektsson T, Zarb G, Worthington P, Eriksson AR (1986) The long-term efficacy of currently used dental implants: A review and proposed criteria of success. Int J Oral Maxillofac Implants 1: 11-25.

25. Swami V, Vijayaraghavan V, Swami V (2016) Current trends to measure implant stability. J Indian Prosthodont Soc 16: 124-130.

26. Meredith N (1998) Assessment of implant stability as a prognostic determinant. Int J Prosthodont 11: 491-501.

27. Barikani H, Rashtak S, Akbari S, Fard MK, Rokn A (2014) The effect of shape, length and diameter of implants on primary stability based on resonance frequency analysis. Dent Res J (Isfahan) 11: 87-91.

28. Melsen B, Costa A (2000) Immediate loading of implants used for orthodontic anchorage. Clin Orthod Res 3: 23-28.

29. Baumgaertel S (2010) Predrilling of the implant site: Is it necessary for orthodontic mini-implants? Am J Orthod Dentofacial Orthop 137: 825-829.

30. Brunski JB (1992) Biomechanical factors affecting the bone-dental implant interface. Clin Mater 10: 153-201.

31. Sennerby L, Roos J (1998) Surgical determinants of clinical success of osseointegrated oral implants: A review of the literature. Int J Prosthodont 11: 408-420.

32. Cochran DL, Schenk RK, Lussi A, Higginbottom FL, Buser D (1998) Bone response to unloaded and loaded titanium implants with a sandblasted and acid-etched surface: A histometric study in the canine mandible. J Biomed Mater Res 40: 1-11.

33. Mistry G, Shetty O, Shetty S, Singh RD (2014) Measuring implant stability: A review of different methods. J Dent Implant 4: 165-169.

34. Patil R, Bharadwaj D (2016) Is primary stability a predictable parameter for loading implant? J Int Clin Dent Res Organ 8: 84-88.

35. Steven I (2011) Guided Wound Healing. Inside Dentistry.

36. Norton M (2013) Primary stability versus viable constraint a need to redefine. Int J Oral Maxillofac Implants 28: 19-21.

37. Dos Santos MV, Elias CN, Cavalcanti Lima JH (2011) The effects of superficial roughness and design on the primary stability of dental implants. Clin Implant Dent Relat Res 13: 215-223.

38. Suzuki S, Kobayashi H, Ogawa T (2013) Implant Stability Change and Osseointegration Speed of Immediately Loaded Photofunctionalized Implants. Implant Dent 22: 481-490.

39. Bajaj G, Bathiya A, Gade J, Mahale Y, Ulemale M, et al. (2017) Primary versus Secondary Implant Stability in Immediate and Early Loaded Implants. Int J Oral Health Med Res 3: 49-54.

40. Abboud M, Rugova S, Orentlicher G (2020) Immediate Loading: Are Implant Surface and Thread Design More Important Than Osteotomy Preparation? Compend Contin Educ Dent 14: 384-386.

41. Abboud M, Koeck B, Stark H, Wahl G, Paillon R (2005) Immediate loading of single-tooth implants in the posterior region. Int J Oral Maxillofac Implants 20: 61-68.

42. Venkatakrishnan CJ, Bhuminathan S, Chandran CR (2017) Dental Implant Site Preparation-A Review. Biomed Pharmacol J 10: 13011304. 
43. Baker JA, Vora S, Bairam L, Kim HI, Davis EL, et al. (2012) Piezoelectric vs. conventional implant site preparation: ex vivo implant primary stability. Clin Oral Implants Res 23: 433-437.

44. Atieh MA, Alsabeeha NHM, Tawse-Smith A, Duncan WJ (2018) Piezoelectric versus conventional implant site preparation: $A$ systematic review and meta-analysis. Clin Implant Dent Relat Res 20: 261-270.

45. Vercellotti T, Stacchi C, Russo C, Rebaudi A, Vincenzi G, et al. (2014) Ultrasonic implant site preparation using piezosurgery: a multicenter case series study analyzing 3,579 implants with a 1- to 3-year followup. Int J Periodontics Restorative Dent 34: 11-18.

46. Stacchi C, Vercellotti T, Torelli L, Furlan F, Di Lenarda R (2013) Changes in implant stability using different site preparation techniques: twist drills versus piezosurgery. A single-blinded, randomized, controlled clinical trial. Clin Implant Dent Relat Res 15: 188-197. 